\title{
Pomological, Organoleptic and Biochemical Characterizations of Tunisian Pomegranate Fruits Punica granatum L.
}

\author{
Manel Mekni, Wafa Kharroubi, Imed Cheraief, Mohamed Hammami \\ Biochemistry Laboratory, LR12ES05 “Nutrition-Functional Foods and Vascular Health”, Faculty of Medicine, University of \\ Monastir, Monastir, Tunisia \\ Email: manelmekni22@gmail.com
}

How to cite this paper: Mekni, M., Kharroubi, W., Cheraief, I. and Hammami, M. (2019) Pomological, Organoleptic and Biochemical Characterizations of Tunisian Pomegranate Fruits Punica granatum L. American Journal of Plant Sciences, 10, 1181-1195.

https://doi.org/10.4236/ajps.2019.107084

Received: May 29, 2019

Accepted: July 26, 2019

Published: July 29, 2019

Copyright $\odot 2019$ by author(s) and Scientific Research Publishing Inc. This work is licensed under the Creative Commons Attribution International License (CC BY 4.0).

http://creativecommons.org/licenses/by/4.0/

\begin{abstract}
Pomological characterization and biochemical study were conducted on five pomegranate fruits cultivars. Results show statistically significant difference between varieties. Indeed, pomegranate seeds play a key role in determining the pomological quality of the fruit. Interestingly, Kalai ranks first with $256.06 \mathrm{~g}$ of the mass of fresh seeds which has $73 \%$ of the Total fresh weight (TFW). Besides, the mass of fresh seeds and TFW showed a significant negative correlation with the percentage of fresh peel $(r=-0.987$ and $r=-0.930$, respectively, $\mathrm{p}<0.01$ ). Parallelly, two major sugars were detected in seeds: glucose, fructose followed by arabinose. Meanwhile, malic and citric acids are both main organic acids accumulated in pomegranate seeds. By determining the acidity index "AI", citric acid was found to be the most predominant organic acid in sour pomegranate varieties like Kalai and Garsi. Though, Tounsi and Zahri variety are the sweetest, thus, having least amounts of citric acid and highest AI levels.
\end{abstract}

\section{Keywords}

Pomegranate, Seeds, Peel, Organic Acids, Sugars, Acidity Index

\section{Introduction}

Pomegranate is generally cultivated in the Mediterranean basin, and in regions of Southern Asia, in India and in North and South America, where high temperatures allow a good fruit ripening. Its successful adaptation to the Mediterranean climate has produced a wide diffusion in various countries thus originating several local genotypes along the centuries [1].

As for many fruit species, pomegranate fruit maturity status is commonly as- 
sessed based on external (skin) colour, juice colour and acidity of juice [2].

Furthermore, the acceptability of pomegranate to the consumer and processor depends on a combination of several quality attributes that are related to the physico-chemical and mechanical properties including skin colour, absence of physical defects sugar content, acidity and flavour [2].

Indeed, pomegranate varieties differ in their taste, ranging from sweet to sour [3] which is determined mainly by organic acid-sugar quantitative and qualitative content balance of the fruit. The desired pomegranate taste varies, however, in different countries and regions [1]. Besides, these compounds (organic acids and sugars) serve as unequivocal markers for sensory attributes assessment and genotype characterization [4].

In Tunisia, pomegranate is one of the most important fruit trees. According to the first forecasts published by the Ministry of Agriculture, Water Resources and Fisheries, the production of grenades will reach 75,000 tons for the 2018-2019 season, compared with 74.5 in the previous year, of which 25,000 tonnes come from Gabes, 13,000 tonnes from Beja and 9500 tonnes from Kairouan [5]. Almost all these productions are based on a few cultivars, with interesting market characteristics, despite the quite large number of local ecotypes listed. However, there is scarcity in seed morphological and chemical characterization of local cultivars of pomegranate despite their high potential of valorisation [4]. Consequently, more information is needed on the morpho-pomological and chemical characteristics of the different genotypes localized in various Tunisia; to capitalize on the potential benefits of pomegranate cultivation.

The purpose of this study consists of pomological and morphological characterization of some Tunisian pomegranate varieties, along with organic acid and sugar profiles as well as their interrelation in order to better understand the potential impact of these factors on consumer preferences.

\section{Material and Methods}

\subsection{Fruits Sampling}

Five different cultivars of Tunisian origin and derived from three regions respectively, "Tounsi" from "Beja" (36 $\left.33^{\circ} \mathrm{N}, 9^{\circ} 25^{\prime} \mathrm{E}\right)$, "Chelfi", "Garsi” and "Zahri" from "Sousse" $\left(35^{\circ} 57^{\prime} \mathrm{N}, 10^{\circ} 27^{\prime} \mathrm{E}\right)$ and "Kalai" from "Kairouan" $\left(35^{\circ} 67^{\prime} \mathrm{N}\right.$, $10^{\circ} 099^{\prime} \mathrm{E}$ ) in October 2015. A group consisting of 09 mature pomegranate fruits per cultivar were sampled at ripe stage as following: three trees of the same cultivar are randomly selected, from each one, mature fruits three are collected. The three fruits from the same tree designating a repetition to finally have three repetitions each formed of three pomegranate fruits. Samples were immediately weighted, then peels and seeds (arils) were carefully separated by hand. Both peels and seeds were weighted separately. The number of fresh seeds per fruit was manually counted for all samples. Peels were dried in oven at $40^{\circ} \mathrm{C}$ until constant weight, then were crushed and sieved to obtain fine powders and stocked away from light at room temperature for further use. 


\subsection{Simultaneous Determination of Soluble Sugars and Organic Acids as Their Trimethylsilyl (TMS) Derivatives in Pomegranate Fruits by Gas Chromatography (GC)}

\subsubsection{Samples' Extraction and Preparation for GC}

In a glass flask $5 \mathrm{ml}$ of $80 \%$ ethanol are added to $50 \mathrm{mg}$ of previously prepared pomegranate powder. The sample is placed in a water bath at $70^{\circ} \mathrm{C}$ for $5 \mathrm{~min}$ utes. The supernatant is then recovered in a $15 \mathrm{ml}$ flask. The extraction is repeated a second time and the total supernatant is filtered. The filtrate obtained is placed in a water bath at $70^{\circ} \mathrm{C}$ for $24 \mathrm{~h}$ and then placed in the oven at $70^{\circ} \mathrm{C}$ for 5 minutes for further evaporation until complete drying [6]. Dried extracts were converted into trimethylsilyl ethers with a silylation mixture previously prepared as follows: $1 \mathrm{ml}$ of pyridine, $100 \mu \mathrm{l}$ of hexamethyldisilazane (HMDS) and $50 \mu \mathrm{l}$ of chlorotrimethylsilane (TMCS). After 24 hours of incubation at room temperature, $1 \mu \mathrm{l}$ of the solution of the silylated extracts are injected into the chromatographic system. D-salicin solution was used as internal standard [6].

\subsubsection{GC Analysis}

The trimethylsilyl ethers of sugars were analyzed by gas chromatography on a capillary column as described by Bartolozzi et al. [6], using a Hewlett-Packard 5890 series II gas chromatograph equipped with a flame ionization detector (FID) system and an HP-5MS column $(30 \mathrm{~m} \times 0.25 \mathrm{~mm})$. Individual sugars and acids were identified by comparison of their retention times with the corresponding standards (standards of sugars and organic acids previously prepared and injected to the capillary column). Injector and detector temperatures were $280^{\circ} \mathrm{C}$ and $300^{\circ} \mathrm{C}$, respectively. The temperature of the oven follows a cycle starting with a temperature of $180^{\circ} \mathrm{C}$ which persists for one minute; then increases with a flow rate of $5^{\circ} \mathrm{C} / \mathrm{min}$ up to $290^{\circ} \mathrm{C}$.

\subsection{Statistical Analysis}

All data were subjected to analyses of variance (ANOVA one-way) using SPSS.16.0 (SPSS, Chicago, IL, USA). The data shown are mean values $(n=3)$ and the significance of the differences was compared using Duncan multiple range test at $\mathrm{p}<0.05$ probability level. The Hierarchical cluster analysis (dendrogram) based on the pomological characteristics of each cultivar, was carried out using the same software SPSS.16.0 (SPSS, Chicago, IL, USA). Simple associations between variables were calculated as the Pearson correlation. Principal component analysis (PCA) was carried out and the individual sugar contents as well as the individual organic acids content of each cultivar were used as variables in PCA using XLStat-Pro version 7.5.2 for Windows (Addinsoft, New York, USA).

\section{Results and Discussion}

\subsection{Pomological Characterization of Pomegranate Fruits}

The results presented in Table 1 show statistically significant difference between 
varieties. Among them, Chelfi has the largest size with a total fresh weight (TFW) equal to $361.55 \mathrm{~g}$, while Tounsi has the smallest size with $224.63 \mathrm{~g}$ TFW. Furthermore, the mass of fresh seeds (MFS) varies significantly from one cultivar to another. The Kalai variety ranks first with $256.06 \mathrm{~g}$ which has $73 \%$ of the TFW. While the variety Tounsi comes last with $109.75 \mathrm{~g}$ (49\% of the TFW, Figure 1).

Thus, the proportion of fresh seeds (\%) relative to the TFW is, in ascending order, as follows: Tounsi $>$ Zahri $>$ Garsi $>$ Chelfi $>$ Kalai. In most studied cultivars, proportions (percentages) of fresh peel compared to TFW are lower than those of the pulp (seeds) and range from $27 \%$ to $42 \%$. Except for the case of Tounsi where peel present almost half of the fruit's TFW with 51\% (Figure 1). The percentages of seeds compared to peel presented by our samples are higher than those found by Martínez et al. [7] who reported seed rates (in\%) between $53.4 \%$ and $61.2 \%$ in five Moroccan pomegranate varieties. Additionally, Fadavi et al. [8] found that the average TFW of mature pomegranate fruits varies between 250 and $300 \mathrm{~g}$. It is noticed that the mass of Chelfi variety reaches up to more than $361 \mathrm{~g}$.

Meanwhile, Zaouay and Mars [9] reported differences between the pomological characteristics of some Tunisian cultivars (total mass and seeds mass) although they are almost the same varieties tested in our study. Indeed, they recorded TFW ranging between 590.80 and $434.75 \mathrm{~g}$ for Chelfi and Tounsi, and between $253.00 \mathrm{~g}$

Table 1. Pomological characteristics of five Tunisian varieties of pomegranate.

\begin{tabular}{|c|c|c|c|c|c|}
\hline & Kalai & Garsi & Zahri & Chelfi & Tounsi \\
\hline Fresh seeds mass (g) & $256.06 \pm 23.34^{c}$ & $194.65 \pm 18.78^{b}$ & $177.18 \pm 40.99^{\mathrm{b}}$ & $239.4 \pm 40.54^{\mathrm{c}}$ & $109.57 \pm 5.55^{\mathrm{a}}$ \\
\hline Fresh peel mass (g) & $100.22 \pm 15.58^{\mathrm{a}}$ & $131.77 \pm 15.48^{\mathrm{b}}$ & $128.59 \pm 22.13^{\mathrm{b}}$ & $122.14 \pm 30.58^{\mathrm{a}, \mathrm{b}}$ & $115.057 \pm 18.49^{\mathrm{a}, \mathrm{b}}$ \\
\hline Total fresh weight (whole fruit) (g) & $356.28 \pm 35.03^{\mathrm{b}}$ & $326.43 \pm 21.35^{\mathrm{a}, \mathrm{b}}$ & $305.77 \pm 61.46^{\mathrm{a}, \mathrm{b}}$ & $361.55 \pm 49.81^{\mathrm{a}, \mathrm{b}}$ & $224.63 \pm 32.41^{\mathrm{a}}$ \\
\hline
\end{tabular}

Means with different letters in the same column were significantly different at the level of $\mathrm{p}<0.05$.
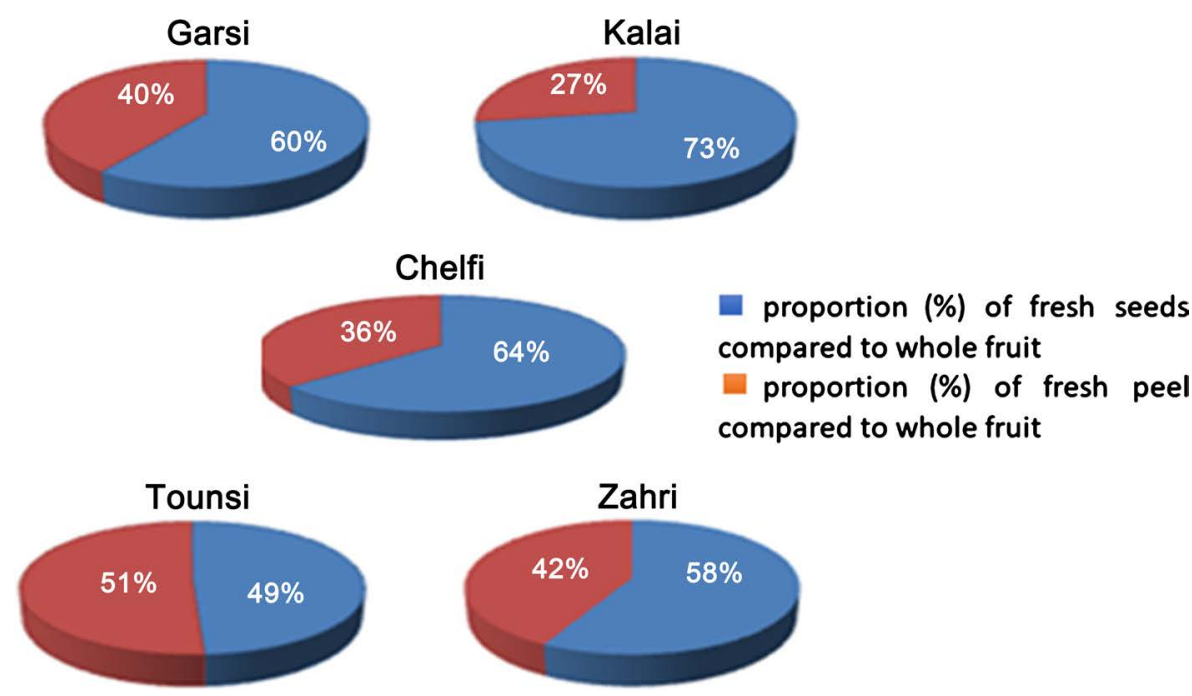

Figure 1. Proportions variations (percentages) of fresh seeds and peels in five Tunisian pomegranate varieties. 


\subsection{4 g for Zahri and Garsi varieties.}

Compared to our results, these differences can be attributed to the diversity that occurs in pomegranate genetic resources originating from hybridization associated with vegetative and sexual propagation [10] which have given rise to a wide variety of cultivars. In Tunisia, more than 60 cultivars have been recorded [11].

We also note the diversity of the geographical location of our cultivars compared to those used by Zaouay and Mars [9]. Indeed, samples in our study namely Gabsi and Tounsi, are coming from the region of Testour (Beja), in northern Tunisia, and cultivars Zahri, Chelfi and Garsi are coming from "Sidi Bou Ali" (Sousse, coastal region). Meanwhile, they have used these same varieties but originating from different regions [9].

Referring to the dendrogram based on the square of the Euclidean distance illustrated in Figure 2, we note that the hierarchical cluster analysis based on the pomological and morphological characteristics subdivides the varieties into four different poles. Indeed, the varieties Kalai and Tounsi have great similarity and thus forming the first group discriminated by this analysis. On the other hand, these two varieties are less related to Garsi variety. The three previous cultivars thus forming the second pole, which itself has a certain degree of similarity with Chelfi variety and constitutes the third group distinguished by hierarchical analysis. However, Zahri variety seems to have less similarity with the previous varieties and thus forming a monopoly compared to the rest of the tested cultivars.

The importance of morphological features and multivariate analyses for the characterization of pomegranate cultivars has been highlighted in some studies [2] [12] [13]. In fact, the identification of pomegranate cultivars is traditionally based on morphological criteria. However, close genetic relationships as well as morphological changes due to the environment are major constraints for the correct identification of cultivars [14]. In Tunisia, the characterization and identification of the pomegranate genetic material is very important, since the same pomegranate cultivar may have several local names and the same local name may refer to different pomegranate cultivars. Characterization based on morphological markers is commonly used to solve problems of duplication of genetic material [9].

\section{Dendrogram using Average Linkage (Between Groups)}

Rescaled Distance Cluster Combine

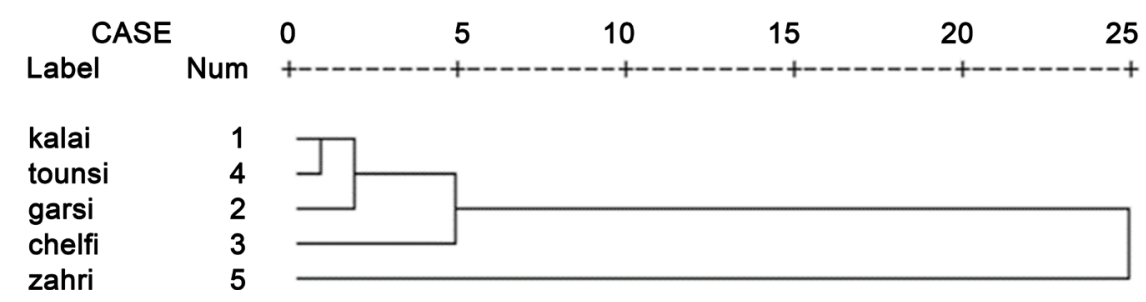

Figure 2. Dendrogram (based on the square of the Euclidean distance) carried out using morphological characteristics of some Tunisian pomegranate varieties. 
Correlations study between the different pomological characteristics shows that TFW is well correlated with total number of seeds per fresh fruit $(r=0.913$, $\mathrm{p}<0.01)$ as well as with the mass of fresh seeds (MFS) per fruit $(\mathrm{r}=0.976, \mathrm{p}<0.01)$. This latter (MFS) are also highly correlated to the percentage of fresh seeds per fruit $(\mathrm{r}=0.987, \mathrm{p}<0.01)$. we also noted that the percentage of fresh peel per fruit is negatively correlated with TFW ( $\mathrm{r}=-0.930, \mathrm{p}<0.01)$ and MFS $(\mathrm{r}=-0.987, \mathrm{p}<0.01)$.

These correlations show that in the case of the studied varieties (Chelfi, Kalai, Zahri, Tounsi and Garsi), seeds play a key role in determining the pomological quality of pomegranates. Indeed, the fruits of these varieties provide the maximum of seeds as well as the minimum of peels, such a fruit is probably of great calibre by dint of its richness in juicy pulp but not because it contains more peels; which present a satisfying characteristic of the consumers requirements. It should be noted that such a characteristic is not often available according to the results of some previous studies. Indeed, Hazel et al. [15] have shown that the size of pomegranate fruit does not necessarily increase the proportion of the edible part, it is rather the number and the mass of the seeds which directly contribute to the improvement of the pomological quality of pomegranate fruits. Our results could then have a positive impact on the studied local varieties by promoting their commercialization and integration on local or even international markets.

\subsection{Organoleptic Characterization of Pomegranate Seeds}

\subsubsection{Determination of Individual Sugars}

The individual sugars identified by capillary column gas chromatography (GC) of pomegranate cultivars are presented in Table 2. A total of 12 sugars is identified

Table 2. Individual sugar content $(\mathrm{g} / 100 \mathrm{~g})$ identified in five Tunisian pomegranate varieties.

\begin{tabular}{|c|c|c|c|c|c|}
\hline & Chelfi & Garsi & Zahri & Tounsi & Kalai \\
\hline Arabinose & $0.82 \pm 0.21^{\mathrm{a}, \mathrm{b}}$ & $0.44 \pm 0.07^{\mathrm{a}}$ & $0.61 \pm 0.07^{\mathrm{a}, \mathrm{b}}$ & $0.96 \pm 0.05^{b, c}$ & $1.32 \pm 0.4^{\mathrm{c}}$ \\
\hline Fructose & $3.14 \pm 0.88^{\mathrm{b}, \mathrm{c}}$ & $1.61 \pm 0.12^{\mathrm{a}}$ & $3.42 \pm 0.15^{\mathrm{c}}$ & $6.1 \pm 0.34^{\mathrm{d}}$ & $2.11 \pm 0.58^{\mathrm{a}, \mathrm{b}}$ \\
\hline Glucose & $4.57 \pm 0.84^{\mathrm{a}}$ & $4.45 \pm 0.46^{\mathrm{a}}$ & $6.35 \pm 0.19^{\mathrm{b}}$ & $9.6 \pm 0.92^{c}$ & $3.43 \pm 0.06^{\mathrm{a}}$ \\
\hline Inositol & $0.13 \pm 0.02^{\mathrm{b}}$ & $0.01 \pm 0.00^{\mathrm{a}}$ & $0.1 \pm 0.01^{\mathrm{b}}$ & $0.18 \pm 0.04^{\mathrm{c}}$ & $0.01 \pm 0.00^{\mathrm{a}}$ \\
\hline Mannitol & $0.04 \pm 0.01^{\mathrm{a}}$ & $0.02 \pm 0.00^{\mathrm{a}}$ & $0.03 \pm 0.00^{\mathrm{a}}$ & $0.03 \pm 0.03^{\mathrm{a}}$ & $0.04 \pm 0.00^{\mathrm{a}}$ \\
\hline Mannose & $0.01 \pm 0.00^{\mathrm{a}}$ & $0.42 \pm 0.06^{c}$ & $0.02 \pm 0.00^{\mathrm{a}}$ & $0.03 \pm 0.01^{\mathrm{a}}$ & $0.13 \pm 0.02^{\mathrm{b}}$ \\
\hline Raffinose & $0.01 \pm 0.00^{\mathrm{b}}$ & $0.02 \pm 0.00^{c}$ & $0.01 \pm 0.00^{\mathrm{b}}$ & $0.02 \pm 0.00^{c}$ & $0.00 \pm 0.00^{\mathrm{a}}$ \\
\hline Rhamnose & $0.04 \pm 0.01^{\mathrm{a}}$ & $0.34 \pm 0.14^{\mathrm{b}}$ & $0.02 \pm 0.00^{\mathrm{a}}$ & $0.04 \pm 0.01^{\mathrm{a}}$ & $0.72 \pm 0.17^{\mathrm{c}}$ \\
\hline Ribose & $0.00 \pm 0.00^{\mathrm{b}}$ & $0.01 \pm 0.00^{\mathrm{a}}$ & $0.00 \pm 0.00^{\mathrm{a}}$ & $0.01 \pm 0.00^{\mathrm{a}}$ & $0.01 \pm 0.00^{\mathrm{a}}$ \\
\hline Saccharose & $0.14 \pm 0.04^{\mathrm{b}}$ & $0.04 \pm 0.00^{\mathrm{a}}$ & $0.14 \pm 0.02^{\mathrm{b}}$ & $0.37 \pm 0.04^{\mathrm{c}}$ & $0.07 \pm 0.02^{\mathrm{a}}$ \\
\hline Threalose & $0.06 \pm 0.01^{\mathrm{a}}$ & $0.07 \pm 0.02^{\mathrm{a}}$ & $0.04 \pm 0.01^{\mathrm{a}}$ & $0.05 \pm 0.01^{\mathrm{a}}$ & $0.05 \pm 0.01^{\mathrm{a}}$ \\
\hline Xylose & $0.22 \pm 0.04^{\mathrm{b}, \mathrm{c}}$ & $0.28 \pm 0.04^{c}$ & $0.01 \pm 0.05^{\mathrm{a}}$ & $0.15 \pm 0.00^{\mathrm{a}, \mathrm{b}}$ & $0.12 \pm 0.04^{\mathrm{a}}$ \\
\hline Total & $9.18 \pm 2.06^{\mathrm{a}, \mathrm{b}}$ & $7.71 \pm 0.91^{\mathrm{a}}$ & $10.75 \pm 0.5^{b}$ & $17.54 \pm 1.45^{\mathrm{c}}$ & $8.01 \pm 1.3^{\mathrm{a}, \mathrm{b}}$ \\
\hline
\end{tabular}

Means with different letters in the same column were significantly different at the level of $\mathrm{p}<0.05$. 
of which both fructose and glucose were major sugars detected in pomegranate seeds. Their proportions vary respectively from 1.61 (Garsi) to $6.1 \mathrm{~g} / 100 \mathrm{~g}$ of resorcinol equivalent (Tounsi) and from 3.43 (Kalai) to $9.6 \mathrm{~g} / 100 \mathrm{~g}$ (Tounsi), followed by arabinose (0.44 (Chelfi) to $1.32 \mathrm{~g} / 100 \mathrm{~g}$ (Kalai)).

Thus, the total sugar content of pomegranate fruits, which varies between 7.71 and $17.54 \mathrm{~g} / 100 \mathrm{~g}$ ) consists essentially of fructose and glucose (Figure 3), in addition to lower amounts of arabinose.

The predominance of fructose and glucose found in this study is consistent with all previous works. However, the results differ regarding the main sugar (fructose or glucose). Indeed, some studies reported that fructose concentrations are higher than those of glucose [16] [17] [18].

Schwartz et al. [19] [20] found equal amounts of these two sugars in 10 pomegranate varieties, while some other studies [21] [22] [23] found results similar to ours, since glucose is predominant in all tested cultivars (Figure 3).

In addition, less prevalent sugars were identified such as inositol mainly detected in Chelfi and Tounsi varieties ( 0.13 and $0.18 \mathrm{~g} / 100 \mathrm{~g}$, respectively). However, mannose and rhamnose are modestly present in Kalai and Garsi varieties ( 0.13 and $0.42 \mathrm{~g} / 100 \mathrm{~g} ; 0.72$ and $0.34 \mathrm{~g} / 100 \mathrm{~g}$, respectively). Although sucrose could be identified in all tested samples, its distribution was quantitatively variable $(0.37 \mathrm{~g} / 100 \mathrm{~g}$ for Tounsi, $0.14 \mathrm{~g} / 100 \mathrm{~g}$ for Chelfi and Zahri, respectively; and 0.04 and $0.07 \mathrm{~g} / 100 \mathrm{~g}$ for Garsi and Kalai, respectively).

Legua et al. [24] found negligible levels of sucrose in some Spanish pomegranates, while Hasnaoui et al. [4] who worked on Tunisian varieties did not detect the presence of this sugar in their samples. However, xylose was present in all tested varieties (from $0.28 \mathrm{~g} / 100 \mathrm{~g}$ in Garsi to $0.12 \mathrm{~g} / 100 \mathrm{~g}$ in Kalai). Moreover, small amounts of ribose, raffinose and mannitol have been detected.

For a better understanding of results, a principal component analysis (PCA) was carried out based on individual sugar contents identified in all tested varieties (Figure 4(a)). According to the PCA, (total variance $=77.28 \%$ ) the main

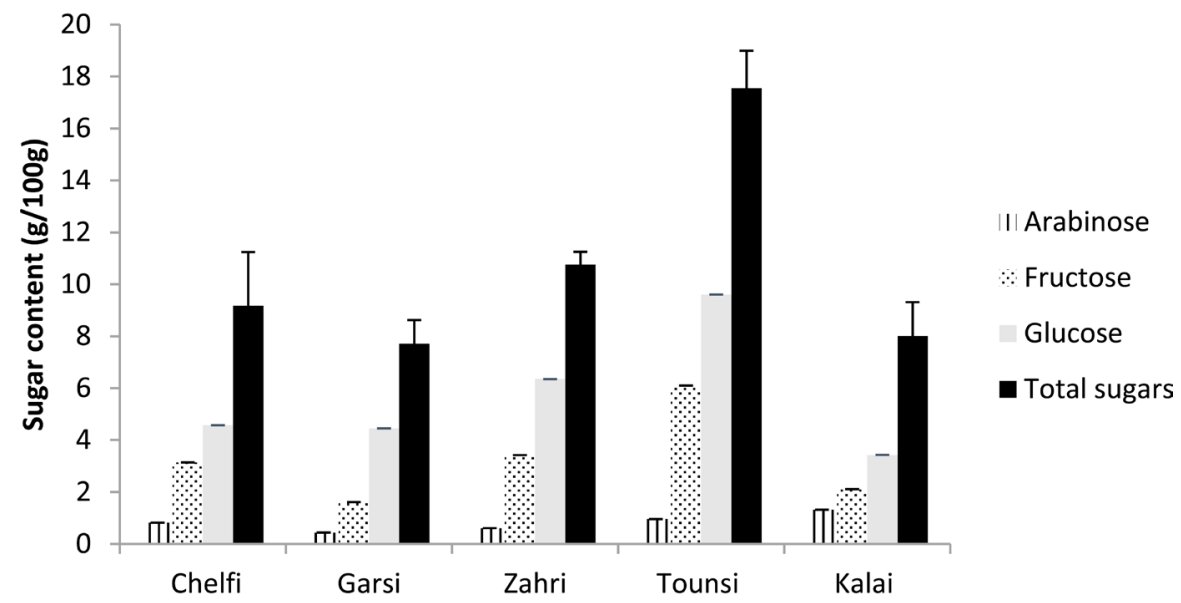

Figure 3. Arabinose, fructose, glucose and total sugars (g/100 g) contents identified in five Tunisian pomegranate varieties. 


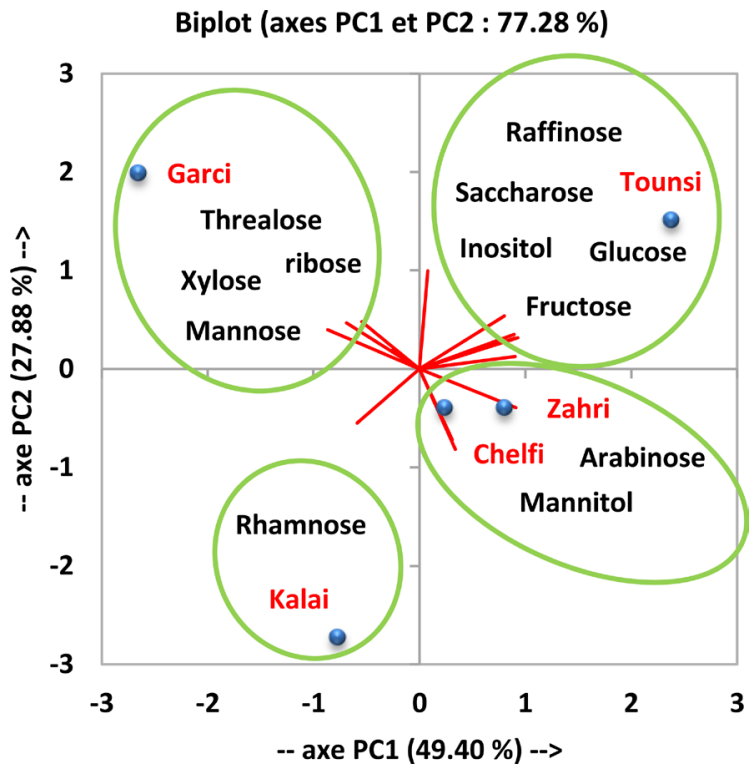

(a)

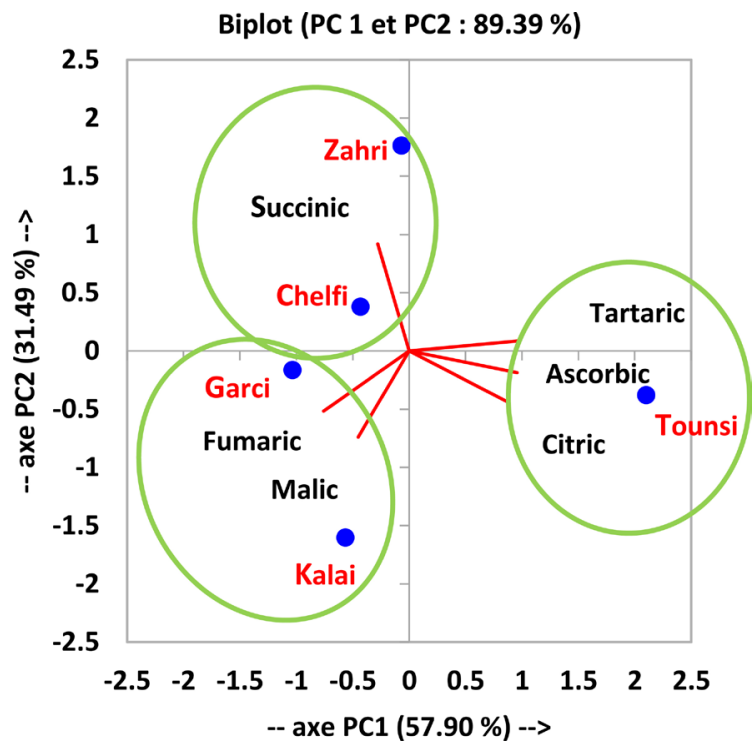

(b)

Figure 4. (a) Principal component analysis based on individual sugar contents identified in the various tested pomegranate varieties; (b) Principal component analysis based on the organic acid contents identified in the various tested varieties of pomegranate.

axis 1 (PC1) is positively correlated with the varieties Tounsi, Zahri and Chelfi, while Garsi and Kalai are negatively correlated with PC1.

Referring to Figure 4(a), four different groups of individual sugars could be distinguished. The first two groups are associated with varieties positively correlated with PC1 while the second two groups are associated with cultivars negatively correlated with PC1. Thus, we note that Tounsi variety is characterized by its high sugar content by generating a panoply of sugars such as fructose and glucose, which are the main sugars of pomegranates, as well as sucrose, raffinose and inositol. In addition, arabinose and mannitol are mainly generated by Zahri 
and Chelfi varieties. The variety Kalai seems to be low in sugars by providing essentially rhamnose. However, Garsi variety is characterized by the dominance of four main sugars including ribose, mannose, xylose and threalose.

It is evident that the distribution of sugar content is quantitatively and qualitatively variable within cultivars. These differences could be attributed to the diversity of agro-climatic conditions, but also to the effect of cultivar (genotype) which has a major impact on sugars accumulation in pomegranate fruits.

\subsubsection{Determination of Individual Organic Acids}

A total of six organic acids were detected by GC, namely ascorbic acid, citric acid, fumaric acid, malic acid, succinic acid and tartaric acid (Table 3). However, neither oxalic acid nor acetic acid which used to be identified in some previous studies [4] [25] could be detected in our samples. Meanwhile, we recorded the presence of two major organic acids; citric acid ranging from 1.4 (Garsi) to $2.86 \mathrm{~g} / 100 \mathrm{~g}$ (Tounsi) and malic acid starting from $0.6 \mathrm{~g}$ (Tounsi) to $2.5 \mathrm{~g} / 100 \mathrm{~g}$ (Kalai). Similar results were reported by most studies of organic acids composition in pomegranate fruits [4] [26].

The acid content (acidity) is an important parameter of pomegranate maturity since it plays a major role in the development of juice flavour [26]. Concentration and composition of organic acids are also essential factors in determining consumer perception of both sweetness and acidity in pomegranate fruit [3] [27]. Hasnaoui et al. [4] reported that citric acid is the major organic acid in sour cultivars while in soft cultivars malic acid is predominant. Thus, strong correlation between citric acid and pomegranate fruit acidity could be suggested. This correlation has been clearly established for the sour (acidic) and sweet cultivars of pomegranates from Turkey [23] and Spain [16]. Similar results for major organic acids as well as their distribution in sour-sweet accessions from various countries have already been reported [16] [17] [19] [20] [23] [28] [29], although some authors do not give identical specifications to the classification of the studied accessions. For Tunisian pomegranates, levels of these two organic acids are generally compatible with previous studies despite a large variation in accessions [4].

Table 3. Organic acids Content ( $\mathrm{g} / 100 \mathrm{~g}$ ) identified at five Tunisian pomegranate varieties.

\begin{tabular}{|c|c|c|c|c|c|}
\hline Organic acids & Chelfi & Garsi & Zahri & Tounsi & Kalai \\
\hline Ascorbic Acid & $0.03 \pm 0.01^{\mathrm{a}}$ & $0.04 \pm 0.00^{\mathrm{a}}$ & $0.02 \pm 0.00^{\mathrm{a}}$ & $2.28 \pm 0.46^{\mathrm{b}}$ & $0.06 \pm 0.01^{\mathrm{a}}$ \\
\hline Citric Acid & $1.52 \pm 0.35^{\mathrm{a}}$ & $1.4 \pm 0.07^{\mathrm{a}}$ & $1.68 \pm 0.05^{\mathrm{a}}$ & $2.86 \pm 0.17^{\mathrm{b}}$ & $2.19 \pm 0.09^{\mathrm{a}, \mathrm{b}}$ \\
\hline Fumaric Acid & $0.01 \pm 0.00^{\mathrm{b}}$ & $0.01 \pm 0.00^{\mathrm{b}}$ & $0.00 \pm 0.00^{\mathrm{b}}$ & $0.00 \pm 0.00^{\mathrm{a}}$ & $0.01 \pm 0.00^{\mathrm{b}}$ \\
\hline Malic Acid & $0.47 \pm 0.18^{\mathrm{a}}$ & $1.42 \pm 0.48^{\mathrm{b}}$ & $0.69 \pm 0.07^{\mathrm{a}}$ & $0.6 \pm 0.16^{\mathrm{a}}$ & $2.5 \pm 0.03^{c}$ \\
\hline Succinic Acid & $0.01 \pm 0.00^{\mathrm{a}, \mathrm{b}}$ & $0.01 \pm 0.00^{\mathrm{a}}$ & $0.03 \pm 0.01^{\mathrm{a}, \mathrm{b}}$ & $0.00 \pm 0.00^{\mathrm{b}}$ & $0.00 \pm 0.00^{\mathrm{a}}$ \\
\hline Tartaric Acid & $0.03 \pm 0.01^{\mathrm{a}}$ & $0.01 \pm 0.00^{\mathrm{a}}$ & $0.03 \pm 0.02^{\mathrm{a}, \mathrm{b}}$ & $0.06 \pm 0.01^{\mathrm{b}}$ & $0.02 \pm 0.0^{\mathrm{a}}$ \\
\hline Total Acids & $2.07 \pm 0.55^{\mathrm{a}}$ & $2.89 \pm 0.5^{b}$ & $2.45 \pm 0.15^{\mathrm{a}, \mathrm{b}}$ & $5.83 \pm 0.8^{c}$ & $4.78 \pm 0.13^{b, c}$ \\
\hline
\end{tabular}

Means with different letters in the same column were significantly different at the level of $\mathrm{p}<0.05$. 
As for ascorbic acid, Tounsi was the richest variety with $2.28 \mathrm{~g} / 100 \mathrm{~g}$ while minor amounts of this acid were detected in the rest of cultivars. Previous studies have reported the presence of ascorbic acid in pomegranate fruits [4] [18] [23] [26] [30]. In addition, we could identify minor quantities of fumaric, succinic and tartaric acids in some varieties while they were completely absent in some others. Moreover, traces of tartaric and succinic acids were detected for some varieties, while the latter is below the detection limit for Tounsi and Kalai varieties. The presence of both tartaric and succinic acids is also reported by Hasnaoui et al. [4]. In addition, fumaric acid, which is the least common acid in our samples, was present in traces in Chelfi, Garsi and Kalai varieties but completely absent in Tounsi and Zahri varieties.

To better discriminate results, Principal Components Analysis (PCA) is carried out based on the different organic acids detected within studied varieties (Figure 4(b)).

According to the figure, we note that only the variety Tounsi is positively correlated with the axis PC1 (Figure 4(b)). The tartaric, ascorbic and citric acids are associated with this variety forming the first group distinguished by this classification. However, Zahri and Chelfi varieties are negatively associated with the main PC1 axis. Succinic acid is the only acid associated with these two varieties thus forming the second group discriminated by this study. In contrast, fumaric and malic acids are associated with Garsi and Kalai varieties that are also negatively correlated with PC1. This quadruplet is the last group established by this discriminatory study. Therefore, it can be considered that the qualitative and quantitative distribution of organic acids is dependent on the cultivar. However, these differences may be not only due to genetic variation, but also caused by the difference in geographical location from which pomegranate fruits are harvested. Further studies are needed to explain differences in organic acid accumulation by pomegranate cultivars.

\section{Correlation Study between the Measured Parameters}

Although consumers are generally aware of the interrelationship between diet and health, other quality factors must be present in a health promoting food, particularly a superior flavour, before it is widely consumed [31]. Hasnoui et al. [4] suggest that organic acid profiles of fruits play an important role in organoleptic properties by increasing or reducing their palatability since acidity is generally attributed to the release of protons from acids [32], and based on our results, it follows that the citric acid content, being the major organic acid seeds, appears as the main determinant of sourness in pomegranate fruits. Thus, both acidity (or sourness) and sweetness of pomegranate are closely related to the concentration of citric acid [4]. Similar conclusion was advanced for orange [33] and melon [34]. This hypothesis is strongly supported genetically. By studying the acidity inheritance in pomegranate, Jalikop [27] concluded that sourness is dominant over sweetness and that this trait is controlled by a major dominant 
gene. He used "low acid variety" as synonym of "sweet variety" in other words, sweetness and sourness are the "heads and tails" of the same characteristic, at least genetically.

Sugars and organic acids play a major role in determining the quality and maturity of fruit. The ratio of sugars to organic acids is commonly regarded as a good index of fruit quality [4]. Referring to Table 4, this ratio varies from one variety to another, ranging from 1.67 (Kalai) to 4.43 (Chelfi). Therefore, it can be considered that the more the ratio increases, the more acid content increases. In other words, this ratio is linearly correlated with citric acid. To obtain more reliable classification criterion and based on previous study conducted by Hasnaoui et al. [4], we calculated the "Acidity Index:" AI "for pomegranate classification which is the ratio of total sugars to citric acid (Table 4).

This ratio varies among cultivars from 3.66 (Kalai) to 6.39 (Zahri). Hasnaoui et al. [4] suggest that relatively low-level AIs are due to the low levels of sugars they contain. Thus, based on their AI, our samples can be classified according to their decreasing softness as follows: Zahri, Tounsi, Chelfi and finally Garsi and Kalai. Although, these two latter varieties might be less suitable for fresh consumption, acid pomegranate fruits exhibit highly interesting properties, especially for food processing industry. Indeed, their acidity, which is due to their richness in citric acid, is a much sought-after property for meat storage [35] [36].

Besides, AI appears to be a good and reliable criterion for the classification of pomegranate cultivars. Hasnaoui et al. [4] consider that it is more effective than the ratio of organic sugars/acids or that of soluble solids/acidity (TSS/A) known as the "Maturity Index (MI)". As it is assumed that the acidity of pomegranate is governed by the concentration of citric acid, the AI takes this assumption directly in consideration and therefore gives more reliable indication of the acidity of pomegranate and therefore its classification. Further sensometric studies, using larger fruits samples and pomegranate cultivars, are required to validate the effectiveness of the AI and establish accurate scale of classification.

\section{Conclusions}

The study of the pomological characteristics of pomegranate fruits shows a significant variation between varieties, under the effect of geological and genetic

Table 4. Total sugars, total organic acids, ratio of sugars to organic acids (Sug/A.org) and the acidity index (IA) calculated for tested pomegranate varieties.

\begin{tabular}{cccccc}
\hline & Chelfi & Garsi & Zahri & Tounsi & Tounsi \\
\hline Total Sugar $(\mathrm{g} / 100 \mathrm{~g})$ & $9.18 \pm 2.06^{\mathrm{a}, \mathrm{b}}$ & $7.71 \pm 0.91^{\mathrm{a}}$ & $10.75 \pm 0.5^{\mathrm{b}}$ & $17.54 \pm 1.45^{\mathrm{c}}$ & $8.01 \pm 1.3^{\mathrm{a}, \mathrm{b}}$ \\
Total organic Acids $(\mathrm{g} / 100 \mathrm{~g})$ & $2.07 \pm 0.55^{\mathrm{a}}$ & $2.89 \pm 0.5^{\mathrm{b}}$ & $2.45 \pm 0.15^{\mathrm{a}, \mathrm{b}}$ & $5.83 \pm 0.8^{\mathrm{c}}$ & $4.78 \pm 0.13^{\mathrm{b}, \mathrm{c}}$ \\
Sugar/Org. Acid ratio* & 4.43 & 2.66 & 4.38 & 3.01 & 1.67 \\
Acidity Index (AI)* & 6.04 & 5.51 & 6.39 & 6.13 & 3.66 \\
\hline
\end{tabular}

Letters (a, c) in the same column were significantly different at the level of $p<0.05 .{ }^{*}$ Total sugars/total organic acids ratio. ${ }^{*}$ Total sugars/citric acid ratio. 
diversity. The study of the correlations between the different pomological characteristics show that the number of seeds per fruit is significantly correlated with the total mass of peel, as well as the percentage of fresh seeds compared to the whole fruit and the total mass of the fresh fruit. The study of organoleptic characteristics showed that among all individual identified sugars, three major compounds are detected at the level of the so-called five varieties and are glucose, fructose, arabinose. Principal component analysis based on sugars has identified the quantitative and qualitative variations in the levels of sugars which can be attributed to the diversity of agro-climatic conditions, but also to the effect of cultivar (genotype) with a major impact on the accumulation of sugars in pomegranate fruits.

Among a total of six organic acids identified in our samples, citric and malic acids are found in most tested varieties. The ratio of total sugars by citric acid or “Acidity Index:" IA varies among cultivars from 3.66 (Kalai) to 6.39 (Zahri). This ratio appears to be a good and reliable criterion for classifying pomegranate cultivars.

\section{Acknowledgements}

This research was financially supported by the Ministry of High Education, Scientific Research and Technology of Tunisia. The authors gratefully thank Mr. "Rabah Essid" for providing pomegranate samples.

\section{Data Availability Statement}

The [excel, spss, xl-stat] data used to support the findings of this study are available from the corresponding author upon request.

\section{Conflicts of Interest}

The authors declare no conflicts of interest regarding the publication of this paper.

\section{References}

[1] Ferrara, G., Cavoski, I., Pacifico, A., Tedone, L. and Mondelli, D. (2011) Morpho-Pomological and Chemical Characterization of Pomegranate (Punica granatum L.) Genotypes in Apulia Region, South Eastern Italy. Scientia Horticulturae, 130, 599-606. https://doi.org/10.1016/j.scienta.2011.08.016

[2] Al-Said, F.A., Opara, L.U. and Al-Yahyia, R.A. (2009) Physico-Chemical and Textural Quality Attributes of Pomegranate Cultivars (Punica granatum L.) Grown in the Sultanate of Oman. Journal of Food Engineering, 90, 129-134. https://doi.org/10.1016/j.jfoodeng.2008.06.012

[3] Holland, D., Hatib, K. and Bar-Ya'akov, I. (2009) Pomegranate: Botany, Horticulture, Breeding. Horticultural Reviews, 35, 127-191. https://doi.org/10.1002/9780470593776.ch2

[4] Hasnaoui, N., Mars, M., Ghaffari, S., Trifi, M., Melgarejo, P. and Hernandez, F. (2011) Seed and Juice Characterization of Pomegranate Fruits Grown in Tunisia: Comparison between Sour and Sweet Cultivars Revealed Interesting Properties for 
Prospective Industrial Applications. Industrial Crops and Products, 33, 374-381. https://doi.org/10.1016/j.indcrop.2010.11.006

[5] Ministry of Agriculture (2018) Water Resources and Fisheries. Tunisia.

[6] Bartolozzi, F., Bertazza, G., Bassi, D. and Cristoferi, G. (1997) Simultaneous Determination of Soluble Sugars and Organic Acids as Their Trimethylsilyl Derivatives in Apricot Fruits by Gas-Liquid Chromatography. Journal of Chromatography A, 758, 99-107. https://doi.org/10.1016/S0021-9673(96)00709-1

[7] Martínez, J.J., Hernández, F., Haddioui, A., Legua, P., Martíneza, R., El Amine, A. and Melgarejo, P. (2012) Physico-Chemical Characterization of Six Pomegranate Cultivars from Morocco: Processing and Fresh Market Aptitudes. Scientia Horticulturae, 140, 100-106. https://doi.org/10.1016/j.scienta.2012.04.002

[8] Fadavi, A., Barzegar, M. and Azizi, M.H. (2006) Determination of Fatty Acids and Total Lipid Content in Oilseed of 25 Pomegranates Varieties Grown in Iran. Journal of Food Composition and Analysis, 19, 676-680. https://doi.org/10.1016/j.jfca.2004.09.002

[9] Zaouay, F. and Mars, M. (2011) Diversity among Tunisian Pomegranate (Punica granatum) Cultivars as Assessed by Pomological and Chemical Traits. International Journal of Fruit Science, 11, 151-166. https://doi.org/10.1080/15538362.2011.578516

[10] Mars, M. (2000) Pomegranate Plant Material: Genetic Resources and Breeding, a Review. Options Méditerranéennes, Série A, 42, 55-62.

[11] Mars, M. and Marrakchi, M. (1998) Conservation and Valorization of Genetic Resources of Pomegranate (Punica granatum L.) in Tunisia. Plant Genetic Resources Newsletter, 114, 36-39.

[12] Mars, M. and Marrakchi, M. (1999) Diversity of Pomegranate (Punica granatum L.) Germplasm in Tunisia. Genetic Resources and Crop Evolution, 46, 461-467. https://doi.org/10.1023/A:1008774221687

[13] Muradoglu, F., Fikret, B.M. and Ozrenk, K. (2006) Pomegranate (Punica granatum L.) Genetic Resources from Hakkari, Turkey. Research Journal of Agriculture and Biological Sciences, 2, 520-525.

[14] Kaemmer, D., Afza, R., Weising, K., Kahl, G. and Novak, F.J. (1992) Oligonucleotide and Amplification Fingerprinting of Wild Species and Cultivars of Banana (Musa spp). Bio/ Technology, 10, 1030-1035. https://doi.org/10.1038/nbt0992-1030

[15] Wetzstein, H.Y., Zhang, Z., Ravid, N. and Wetzstein, M.W. (2011) Characterization of Attributes Related to Fruit Size in Pomegranate. Hortscience, 46, 908-912. https://doi.org/10.21273/HORTSCI.46.6.908

[16] Melgarejo, P. and Artes, F. (2000) Total Lipid Content and Fatty Acid Composition of Oil Seed from Lesser Known Sweet Pomegranate Clones. Journal of the Science of Food and Agriculture, 80, 1452-1455. https://doi.org/10.1002/1097-0010(200008)80:10<1452::AID-JSFA665>3.0.CO;2-L

[17] Poyrazoglu, E., Gokmen, V. and Artik, N. (2002) Organic Acids and Phenolic Compounds in Pomegranate (Punica granatum) Grown in Turkey. Journal of Food Composition and Analysis, 15, 267-275. https://doi.org/10.1006/jfca.2002.1071

[18] Tezcan, F., Gultekin-Ozguven, M., Diken, T., Ozcelik, B. and Erim, F.B. (2009) Antioxidant Activity and Total Phenolic, Organic Acid and Sugar Content in Commercial Pomegranate Juices. Food Chemistry, 115, 873-877.

https://doi.org/10.1016/j.foodchem.2008.12.103

[19] Schwartz, E., Tzulker, R., Glazer, I., Bar-Ya'akov, I., Weisman, Z., Tripler, E., Bar-Ilan, I., Fromm, H., Borochov-Neori, H., Holland, D. and Amir, R. (2009) En- 
vironmental Conditions Affect the Color, Taste, and Antioxidant Capacity of 11 Pomegranate Accessions' Fruits. Journal of Agricultural and Food Chemistry, 57, 9197-9209. https://doi.org/10.1021/jf901466c

[20] Schwartz, E., Glazer, I., Bar-Ya'akov, I., Matityahu, I., Bar-Ilan, I., Holland, D. and Amir, R. (2009) Changes in Chemical Constituents during the Maturation and Ripening of Two Commercially Important Pomegranate Accessions. Food Chemistry, 115, 965-973. https://doi.org/10.1016/j.foodchem.2009.01.036

[21] Al-Maiman, S.A. and Ahmad, D. (2002) Changes in Physical and Chemical Properties during Pomegranate (Punica granatum L.) Fruit Maturation. Food Chemistry, 76, 437-441. https://doi.org/10.1016/S0308-8146(01)00301-6

[22] Çam, M., Hisil, Y. and Durmaz, G. (2009) Characterisation of Pomegranate Juices from Ten Cultivars Grown in Turkey. International Journal of Food Properties, 12, 388-395. https://doi.org/10.1080/10942910701813917

[23] Ozgen, M., Durgac, C., Serc, S. and Kaya, C. (2008) Chemical and Antioxidant Properties of Pomegranate Cultivars Grown in the Mediterranean Region of Turkey. Food Chemistry, 111, 703-706. https://doi.org/10.1016/j.foodchem.2008.04.043

[24] Legua, P., Melgarejo, H.A., Martinez, J.J., Martinez, R., IIham, H., Hafida, H. and Hernandez, F. (2012) Total Phenols and Antioxidant Capacity in 10 Moroccan Pomegranate Varieties. Journal of Food Science, 71, 115-119. https://doi.org/10.1111/j.1750-3841.2011.02516.x

[25] Aarabi, A., Barzegar, M. and Azizi, M.H. (2008) Effect of Cultivar and Cold Storage of Pomegranate (Punica granatum L.) Juices on Organic Acid Composition. ASEAN Food Journal, 15, 45-55.

[26] Fawole, O.A. and Opara, U.L. (2013) Effects of Maturity Status on Biochemical Content, Polyphenol Composition and Antioxidant Capacity of Pomegranate Fruit Arils (cv. 'Bhagwa') Olaniyi. South African Journal of Botany, 85, 23-31. https://doi.org/10.1016/j.sajb.2012.11.010

[27] Jalikop, S.H. (2007) Linked Dominant Alleles or Inter-Locus Interaction Results in a Major Shift in Pomegranate Fruit Acidity of 'Ganesh' × 'Kabul Yellow'. Euphytica, 158, 201-207. https://doi.org/10.1007/s10681-007-9443-1

[28] Dafny-Yalin, M., Glazer, I., Bar-Ilan, I., Kerem, Z., Holland, D. and Amir, R. (2010) Color, Sugars and Organic Acids Composition in Aril Juices and Peel Homogenates Prepared from Different Pomegranate Accessions. Journal of Agricultural and Food Chemistry, 58, 4342-4352. https://doi.org/10.1021/jf904337t

[29] Pande, G. and Akoh, C.C. (2009) Antioxidant Capacity and Lipid Characterization of Six Georgia-Grown Pomegranate Cultivars. Journal of Agricultural and Food Chemistry, 57, 9427-9436. https://doi.org/10.1021/jf901880p

[30] Gundogdu, M. and Yilmaz, H. (2012) Organic Acid, Phenolic Profile and Antioxidant Capacities of Pomegranate (Punica granatum L.) Cultivars and Selected Genotypes. Scientia Horticulturae, 143, 38-42. https://doi.org/10.1016/j.scienta.2012.05.029

[31] Hilliam, M. (1995) Functional Foods: The Western Consumer Viewpoint. Nutrition Reviews, 54, S189-S194. https://doi.org/10.1111/j.1753-4887.1996.tb03846.x

[32] Sweetman, C., Deluc, L.G., Cramer, G.R., Ford, C.M. and Soole, K.L. (2009) Regulation of Malate Metabolism in Grape Berry and Other Developing Fruits. Phytochemistry, 70, 1329-1344. https://doi.org/10.1016/j.phytochem.2009.08.006

[33] Karadeniz, F. (2004) Main Organic Acid Distribution of Authentic Citrus Juices in Turkey. Turkish Journal of Agriculture and Forestry, 28, 267-271. 
[34] Albuquerque, B., Lidon, F.C. and Barreiro, M.G. (2006) A Case Study on the Flavor Properties of Melon (Cucumis melo L.) Cultivars. Fruits, 1, 333-339. https://doi.org/10.1051/fruits:2006032

[35] Shuming, K., Huang, Y., Decker, E.A. and Hultin, H.O. (2009) Impact of Citric Acid on the Tenderness, Microstructure and Oxidative Stability of Beef Muscle. Meat Science, 82, 113-115. https://doi.org/10.1016/j.meatsci.2008.12.010

[36] Naveena, B.M., Sen, A.R., Vaithiyanathan, S., Babji, Y. and Kondaiah, N. (2008) Comparative Efficacy of Pomegranate Juice, Pomegranate Rind Powder Extract and BHT as Antioxidant in Cooked Chicken Patties. Meat Science, 80, 1304-1308.

https://doi.org/10.1016/j.meatsci.2008.06.005 